\title{
Anastrozole-Induced Carpal Tunnel Syndrome: Results From the International Breast Cancer Intervention Study II Prevention Trial
}

\author{
Francesco Spagnolo, Ivana Sestak, Anthony Howell, John F. Forbes, and Jack Cuzick
}

Francesco Spagnolo, Ivana Sestak, and Jack Cuzick, Centre for Cancer

Prevention, Wolfson Institute of Preventive Medicine, Queen Mary University of London, London; Anthony Howell, Genesis Breast Cancer

Prevention Centre, University Hospital of South Manchester, Manchester, United Kingdom; and John F. Forbes, Department of Surgical Oncology, University of Newcastle, Newcastle Mater Hospital, New South Wales, Australia

Published online ahead of print at www.jco.org on November 23, 2015.

Supported in part by Cancer Research UK (C569/A5032) and the National Health and Medical Research Council Australia (GNT300755, GNT569213), and in part by AstraZeneca, who also provided anastrozole and matching placebo. This study was sponsored by Queen Mary University of London, London, United Kingdom.

Authors' disclosures of potential conflicts of interest are found in the article online at www.jco.org. Author contributions are found at the end of this article.

Corresponding author: Ivana Sestak, PhD Centre for Cancer Prevention, Wolfson Institute of Preventive Medicine, Queen Mary University of London, Charterhouse Square, London, UK EC1M 6BQ; e-mail: i.sestak@qmul.ac.uk.

(C) 2015 by American Society of Clinical Oncology

0732-183X/16/3402w-139w/\$20.00

DOI: 10.1200/JCO.2015.63.4972

\section{Purpose}

Carpal tunnel syndrome (CTS) occurs when the median nerve is compressed at the wrist in the carpal tunnel. It has been suggested that hormonal risk factors may be involved in the pathogenesis of CTS, and a higher incidence of CTS has been reported in randomized clinical trials with aromatase inhibitors (Als) compared with tamoxifen.

\section{Patients and Methods}

This was an exploratory analysis of the International Breast Cancer Intervention Study II, a doubleblind randomized clinical trial in which women at increased risk of breast cancer were randomly assigned to receive anastrozole or placebo. This is the first report of risk factors for and characteristics of CTS in women taking an Al in a placebo-controlled trial.

\section{Results}

Overall, 96 participants with CTS were observed: 65 (3.4\%) in the anastrozole arm and $31(1.6 \%)$ in the placebo arm (odds ratio, 2.16 [1.40 to 3.33]; $P<.001$ ). Ten participants were reported as having severe CTS, of which eight were taking anastrozole $(P=.08)$. Eighteen women $(0.9 \%)$ in the anastrozole arm and six women $(0.3 \%)$ in the placebo arm reported surgical intervention, which was significantly different (odds ratio, 3.06 [1.21 to 7.72], $P=.018$ ). Six women discontinued with the allocated treatment because of the onset of CTS. Apart from treatment allocation, a high body mass index and an a prior report of musculoskeletal symptoms after trial entry were the only other risk factors for CTS identified in these postmenopausal women.

\section{Conclusions}

The use of anastrozole was associated with a higher incidence of CTS but few participants required surgery. Further investigations are warranted into the risk factors and treatment of Al-induced CTS.

\section{J Clin Oncol 34:139-143. (C) 2015 by American Society of Clinical Oncology}

\section{INTRODUCTION}

Carpal tunnel syndrome (CTS) occurs when the median nerve, which runs from the forearm into the hand, is compressed in the carpal tunnel, an osteofibrous, not extensible outlet at the wrist. It is the most common entrapment neuropathy and in most cases is idiopathic. Secondary CTS may be caused by abnormalities of the shape or position of the carpal bones surrounding the tunnel (eg, acromegaly and osteoarthritis) or by the contents of the tunnel (such as synovial hypertrophy, intracanalicular tumors, inflammatory or metabolic tenosynovitis, or abnormal fluid distribution such as in pregnancy). ${ }^{1}$
Diagnosis of CTS is mainly clinical, ${ }^{1}$ with nocturnal acroparaesthesia being the most sensitive symptom. ${ }^{2}$ Paraesthesia in median nerve territory is described as needles, burning sensation, tingling, heaviness, or electric impulses, usually accompanied by pain radiating to the forearm, elbow, or shoulder. Other symptoms include a decrease in strength, morning edema, and cold intolerance. ${ }^{1}$ Additional tests such as nerve conduction studies are not essential for the diagnosis of a typical form of CTS and do not provide any additional evidence compared with clinical assessment. ${ }^{3}$

It has been suggested that hormonal risk factors may be involved in the pathogenesis of CTS. Women have a three times-increased risk of 
developing CTS compared with men, especially around the time of menopause. ${ }^{4,5}$ Pregnancy, ${ }^{6}$ bilateral oophorectomy, ${ }^{7}$ and use of the combined oral contraceptive ${ }^{8}$ have all been identified as risk factors for CTS. In contrast, menopausal hormone replacement therapy (MHT) has been shown to lead to resolution of CTS in menopausal women., ${ }^{9,10}$ Increased risk of CTS has also been reported with third-generation aromatase inhibitors (AIs) anastrozole, ${ }^{11}$ exemestane, ${ }^{12}$ and letrozole, ${ }^{13}$ which have become established adjuvant treatment of postmenopausal women with hormone receptor-positive breast cancer, because they have been shown to significantly lower recurrence rates compared with tamoxifen. ${ }^{14}$ In addition, the International Breast Cancer Intervention Study (IBIS)-II and Mammary Prevention (MAP) 3 trials showed the effectiveness of anastrozole and exemestane in preventing breast cancer in healthy postmenopausal women at high risk of developing the disease. ${ }^{15,16}$ However, musculoskeletal symptoms have been reported significantly more often with AIs when compared with tamoxifen or placebo ${ }^{17,18}$ and may account for nonadherence to treatment, which has been reported to be as high as $25 \%$ during the first year of therapy. ${ }^{19}$ In a multicenter, prospective trial of exemestane versus letrozole, $24.3 \%$ discontinued therapy because of musculoskeletal symptoms. ${ }^{20}$ With many patients with breast cancer taking AIs worldwide, adverse effects that can limit compliance are of growing importance. Available data on CTS and AIs come from clinical studies against tamoxifen in the adjuvant setting. Here, we investigate the characteristics of CTS in women taking anastrozole who are at high risk of developing breast cancer (IBIS-II trial), ${ }^{15}$ without the limitation of the possible confounding effect of tamoxifen or other breast cancer treatments.

\section{PATIENTS AND METHODS}

The IBIS-II study ${ }^{15}$ is a double-blind randomized clinical trial in which women at increased risk of breast cancer were randomly assigned to receive oral anastrozole ( $1 \mathrm{mg} /$ day) or matching placebo for 5 years. Details of trial design, methods, study population, objectives, and results have been described previously. ${ }^{15}$ All participants provided written informed consent before trial entry. Regulatory authorities and ethics committees for all participating centers in 18 countries approved the protocol before enrollment of participants. The trial was performed in accordance with the Declaration of Helsinki (1996 revision) and under the principles of Good Clinical Practice. The IBIS-II trial is registered as an International Standard Randomized Controlled Trial (No. ISRCTN31488319). The study has completed accrual ( $\mathrm{n}=3,864$ ), and follow-up is continuing for enrolled participants.

Patients were included in this analysis if CTS, as reported by the investigator on case report forms, or CTS symptoms occurred at any time during active treatment. CTS symptoms were defined as follows: paraesthesia in the median nerve territory described as needles, burning sensation, tingling, heaviness, or electric impulses usually accompanied by pain radiating to the forearm, elbow or shoulder, decrease of strength, or swelling.

This analysis was based on an intention-to-treat population. One patient was excluded because of CTS at baseline. Analyses of potential risk factors (treatment, age, smoking status, previous MHT use, body mass index [BMI], and other musculoskeletal symptoms [arthralgia]) were based on comparisons of proportions by univariate and multivariate logistic regression (adjusted for all baseline factors). Interactions between treatment and subgroups were based on likelihood ratio tests for an added interaction term. Annual hazard plots were also produced. All $P$ values are two sided, with level of significance at $P=.05$ and all CIs are at the $95 \%$ level. All calculations were performed by use of STATA (version 12.1; STATA, College Station, TX).

\section{RESULTS}

A total of 3,864 women were randomly assigned to receive either anastrozole $(\mathrm{n}=1,920)$ or placebo $(\mathrm{n}=1,944)$. Baseline characteristics are listed in Table 1 and were described in detail elsewhere. ${ }^{15}$ In brief, median age was 59.5 years (interquartile range [IQR], 55.0 to 63.5 years), and almost half of the women (47\%) had used MHT previously. The majority of the women had a BMI of greater than $25 \mathrm{~kg} / \mathrm{m}^{2}$ (69\%) and half of the women were neversmokers (Table 1). Patients' characteristics were well balanced between the two treatment arms (Table 1).

After 6.4 years (4.4 to 8.5) median follow-up, a total of 96 participants with CTS were reported (65 participants [3.4\%] taking anastrozole $v 31$ participants [1.6\%] taking placebo; odds ratio [OR], 2.16 [1.40 to 3.33]; $P<.001)$. Overall, median time to onset of CTS was 1.99 years (IQR, 0.95 to 3.05 years). Figure 1 shows a histogram of newly reported CTS according to treatment arm. Newly reported CTS was higher in the anastrozole arm compared with placebo over the entire course of active treatment, but the difference was particularly evident during the first 2.5 years of treatment (Fig 1).

Women in the anastrozole arm tended to have more severe disease $(P$ for trend $=.09)$. A total of 10 cases of CTS $(0.3 \%)$ were reported as severe: eight $(0.4 \%)$ in the anastrozole arm and two $(0.1 \%)$ in the placebo arm (Table 1). The rate of severe CTS in the anastrozole arm was four times higher compared with the placebo arm, but the difference was statistically not significant (OR, 4.06 (0.86 to 19.16); $P=.076)$. A modest difference in intensity according to treatment arm was also noted for moderate severity, with 17 participants $(0.9 \%)$ in the anastrozole arm compared with 10 participants $(0.5 \%)$ in the placebo arm (OR, 1.73 [0.79 to 3.78], $P=.1$ ). Reports of mild CTS were similar between the two treatment groups (Table 2). Thirty-two women $(0.8 \%)$ reported bilateral CTS and similarly, 31 women $(0.8 \%)$ reported unilateral CTS (Table 2$)$. No significant differences between treatment arms and laterality were observed (Table 2).

Although only 38 women (1.0\%) had some sort of treatment of CTS, the difference between the two treatment arms was statistically significant (OR, 2.21 [1.11 to 4.39], $P=.024$ ) (Table 2). Women could have had more than one intervention for their CTS. Surgery was performed significantly more often in women in the anastrozole arm (18 [0.9\%]) compared with those in the placebo arm (six [0.3\%]) (OR, 3.06 [1.21 to 7.71]; $P=.018)$. A further 14 women

Table 1. Baseline Demographics According to Treatment Allocation

\begin{tabular}{lcc}
\hline $\begin{array}{c}\text { Patient } \\
\text { Demographic }\end{array}$ & $\begin{array}{c}\text { Anastrozole } \\
(\mathrm{n}=1920)\end{array}$ & $\begin{array}{c}\text { Placebo } \\
(\mathrm{n}=1944)\end{array}$ \\
\hline Age, years, mean (SD) & $59.3(5.7)$ & $59.2(5.7)$ \\
$\mathrm{BMI}, \mathrm{kg} / \mathrm{m}^{2}$ & $584(30.4)$ & $570(29.3)$ \\
$\leq 25$ & $696(36.3)$ & $730(37.6)$ \\
$25-30$ & $596(31.0)$ & $600(30.9)$ \\
$>30$ & $894(46.6)$ & $913(47.0)$ \\
Previous MHT use & & $1130(58.1)$ \\
Smoking status & $1060(55.2)$ & $785(40.4)$ \\
Never & $825(43.0)$ & \\
Ever &
\end{tabular}

NOTE: Data are presented as No. (\%) unless indicated otherwise. Abbreviations: BMI, body mass index; $\mathrm{MHT}$, menopausal hormone therapy SD, standard deviation. 


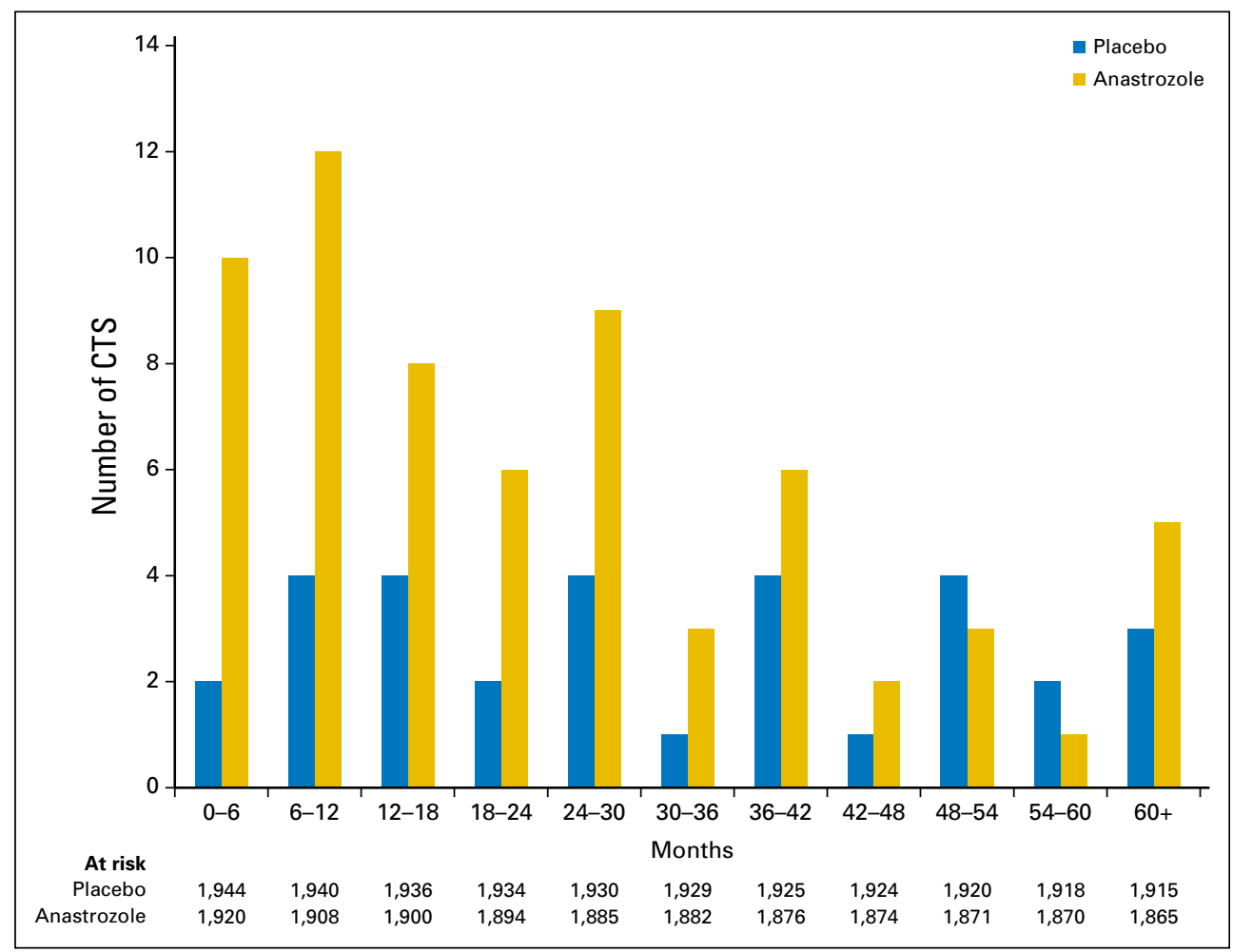

Fig 1. Histogram of newly reported carpal tunnel syndrome (CTS) according to treatment allocation.

were managed with a conservative approach (ie, cortisone injections $[\mathrm{n}=13]$ and/or wrist splint $[\mathrm{n}=11])$. There was no difference between the two treatment arms according to conservative treatment of CTS (Table 2). Median time to resolution was 1.00 year (IQR, 0.27 to 2.07 years), with no significant differences found between treatment arms $(P=.4)$. Treatment was discontinued in a total of 17 women because of the onset of CTS or other adverse events (12 anastrozole $v$ five placebo; OR, 2.44 [0.80 to 8.85]; $P=.08$ ).
Potential risk factors for developing CTS were analyzed and are summarized in Table 3. Age, smoking, and prior MHT were not found to be risk factors for the development of CTS. Women with a BMI between 25 and $30 \mathrm{~kg} / \mathrm{m}^{2}$ and those with a BMI greater than $30 \mathrm{~kg} / \mathrm{m}^{2}$ had a significantly higher risk of developing CTS compared with women with a BMI of $25 \mathrm{~kg} / \mathrm{m}^{2}$ or less (OR, 1.78 [1.07 to 2.96]; $P=.02$ ). Patients with other musculoskeletal symptoms had a significantly higher risk of developing CTS compared with women

\begin{tabular}{|c|c|c|c|c|c|c|}
\hline \multirow[b]{2}{*}{ Clinical Outcome } & \multicolumn{2}{|c|}{ Anastrozole $(n=1920)$} & \multicolumn{2}{|c|}{ Placebo $(n=1944)$} & \multirow[b]{2}{*}{ OR $(95 \% \mathrm{Cl})$} & \multirow[b]{2}{*}{$P$} \\
\hline & No. & $\%$ & No. & $\%$ & & \\
\hline Total & 65 & 3.4 & 31 & 1.6 & 2.16 (1.40 to 3.33$)$ & $<.001$ \\
\hline \multicolumn{7}{|l|}{ Severity } \\
\hline Mild & 20 & 1.0 & 15 & 0.8 & 1.35 (0.69 to 2.65$)$ & $.09 *$ \\
\hline Moderate & 17 & 0.9 & 10 & 0.5 & 1.73 (0.79 to 3.78$)$ & \\
\hline Severe & 8 & 0.4 & 2 & 0.1 & $4.06(0.86$ to 19.16$)$ & \\
\hline Unknown & 20 & - & 4 & - & & \\
\hline \multicolumn{7}{|l|}{ Side } \\
\hline Bilateral & 22 & 1.1 & 10 & 0.5 & 2.24 (1.06 to 4.75$)$ & \\
\hline Unilateral & 18 & 0.9 & 13 & 0.7 & 1.41 (0.69 to 2.88$)$ & \\
\hline Unknown & 25 & 1.3 & 8 & 0.4 & & \\
\hline \multicolumn{7}{|l|}{ Intervention } \\
\hline Yes & 26 & 1.4 & 12 & 0.6 & 2.21 (1.11 to 4.39$)$ & \\
\hline \multicolumn{7}{|l|}{ Type of interventiont } \\
\hline Surgery & 18 & 0.9 & 6 & 0.3 & 3.06 (1.21 to 7.72$)$ & \\
\hline Corticosteroids injection & 8 & 0.4 & 5 & 0.3 & $1.62(0.53$ to 4.97$)$ & \\
\hline Splint & 6 & 0.3 & 5 & 0.3 & 1.22 (0.37 to 3.99$)$ & \\
\hline No & 39 & 2.0 & 19 & 1.0 & & \\
\hline
\end{tabular}




\begin{tabular}{|c|c|c|c|c|c|c|}
\hline \multirow[b]{2}{*}{ Risk Factor } & \multicolumn{2}{|c|}{ Women With CTS } & \multicolumn{2}{|c|}{ Univariate Analysis } & \multicolumn{2}{|c|}{ Multivariate Analysis } \\
\hline & No. & $\%$ & OR $(95 \% \mathrm{Cl})$ & $P$ & OR $(95 \% \mathrm{Cl})$ & $P$ \\
\hline \multicolumn{7}{|l|}{ Treatment } \\
\hline Placebo $(n=1,944)$ & 31 & 1.60 & Reference & & Reference & \\
\hline Anastrozole $(n=1,920)$ & 65 & 3.40 & 2.16 (1.40 to 3.33$)$ & $<.001$ & 2.26 (1.46 to 3.50$)$ & $<.001$ \\
\hline \multicolumn{7}{|l|}{ Age, years } \\
\hline$\leq 60(\mathrm{n}=2,041)$ & 51 & 2.50 & Reference & & & \\
\hline$>60(\mathrm{n}=1,802)$ & 45 & 2.50 & 1.00 (0.67 to 1.50$)$ & .99 & & \\
\hline \multicolumn{7}{|l|}{ Ever-smoker } \\
\hline No $(n=2,190)$ & 54 & 2.50 & Reference & & & \\
\hline Yes $(n=1,610)$ & 41 & 2.60 & $1.03(0.69$ to 1.56$)$ & .87 & & \\
\hline \multicolumn{7}{|l|}{ Previous MHT use } \\
\hline No $(n=2,035)$ & 59 & 2.90 & Reference & & & \\
\hline Yes $(n=1,807)$ & 37 & 2.10 & 0.70 (0.46 to 1.06$)$ & .09 & & \\
\hline \multicolumn{7}{|l|}{$\mathrm{BMI}, \mathrm{kg} / \mathrm{m}^{2}$} \\
\hline$\leq 25(n=1,154)$ & 19 & 1.70 & Reference & & Reference & \\
\hline $25-30(n=1,426)$ & 45 & 3.20 & 1.95 (1.13 to 3.35$)$ & .016 & 1.98 (1.15 to 3.40$)$ & .014 \\
\hline$>30(n=1,196)$ & 31 & 2.60 & 1.59 (0.89 to 2.83 ) & .12 & 1.60 (0.90 to 2.85$)$ & .11 \\
\hline \multicolumn{7}{|l|}{ Arthralgia } \\
\hline No $(n=1,715)$ & 27 & 1.60 & Reference & & Reference & \\
\hline Yes $(n=2,149)$ & 69 & 3.20 & 2.07 (1.32 to 3.25$)$ & .0001 & $1.97(1.25$ to 3.11$)$ & .004 \\
\hline
\end{tabular}

who did not report any musculoskeletal adverse event (3.2\% $v 1.6 \%$; OR, 2.05 [1.29 to 3.34$] ; P=.001)$.

\section{DISCUSSION}

To our knowledge, this is the first analysis of CTS characteristics and risk factors in healthy, postmenopausal women taking anastrozole in a large, randomized, placebo-controlled trial. Two previous studies reported comparative data for anastrozole ${ }^{11}$ and exemestane, ${ }^{12}$ but the comparator was tamoxifen. Our results show a twofold increase in CTS for women who were randomly assigned to anastrozole when compared with placebo.

A higher rate of CTS was observed in this retrospective analysis of the IBIS-II trial (3.4\% anastrozole and $1.6 \%$ placebo) compared with the Arimidex, Tamoxifen, Alone or in Combination (ATAC; $2.6 \%$ anastrozole and $0.7 \%$ tamoxifen) and Intergroup Exemestane Study (IES; $2.8 \%$ exemestane and 0.6\% tamoxifen) studies. This may be a consequence of an increased awareness of this adverse effect by both investigators and patients that led to a more precise reporting of symptoms. The majority of cases of CTS in those taking anastrozole in our study were reported early on ( 0 to 24 months), and the incidence of newly reported CTS decreased thereafter. A similar picture was seen in the ATAC trial, in which most cases of CTS in those taking anastrozole were reported within the first 2 years, and a decline was seen thereafter. ${ }^{11}$

Overall, the incidence of CTS with anastrozole was low (3.4\%) and fewer than two of every 1,000 women discontinued treatment only because of the onset of CTS. In fact, the majority of CTS reported in the anastrozole group was of mild to moderate severity, with approximately $10 \%$ of participants reported as severe and one out of three requiring an intervention of any kind (surgery or corticosteroids/wrist splint). The natural evolution of CTS is usually slow progression, but symptoms may regress spontaneously in approximately one-third of patients. ${ }^{1,21}$ In a large multicenter study, 34\% of patients improved without any intervention, and $45 \%$ were unchanged after 1 year without any treatment and with a short duration of symptoms being the main favorable prognostic factor. ${ }^{22}$ In the ATAC trial, ${ }^{11}$ the rate of surgical interventions was $13 \%$, which was lower than our finding of $25 \%$. In contrast, the IES trial observed a rate of surgeries as high as $69 \% .{ }^{12}$ There is no evidence for a differential activity of these two drugs that can explain this discrepancy. ${ }^{23,24}$ However, the higher risk of developing CTS (OR, $5.33 v \mathrm{OR}, 2.16$ to 3.55) and the higher rate of surgical procedures (69\% $v 13 \%$ to $25 \%)$ observed with exemestane suggest that the risk and severity of CTS may be higher with exemestane than with anastrozole. The management of CTS was not reported uniformly because it was left to the scrutiny of local investigators and the diagnosis is mainly clinical, so the differences between the two classes of AIs may be the consequence of a different approach in reporting and treating this condition.

The pathophysiology of CTS with AIs has yet to be described fully. Studies on biochemical markers of autoimmunity and inflammation show no evidence of a systemic autoimmune/ inflammatory process in the pathogenesis of CTS and other musculoskeletal symptoms. ${ }^{25,26}$ Estrogen deprivation has been hypothesized to be the main explanation for the development of CTS, ${ }^{27}$ as well as other musculoskeletal symptoms. AIs reduce estrogen levels in postmenopausal women, blocking the peripheral conversion of androgenic precursors into estrogen by the aromatase enzyme. Estrogen is known to have antinociceptive effects, ${ }^{28}$ and Felson and Cummings ${ }^{29}$ reported increased pain-related symptoms in women taking an AI; they argue that this may be a consequence of a decreased threshold for pain stimuli. Other investigators $^{30}$ have found that estrogen and progesterone receptors are expressed in the transverse carpal ligament, which forms the roof of the carpal tunnel, and have suggested that female sex hormones may influence the transverse carpal ligament metabolism and directly induce CTS. Morphologic changes in the carpal tunnel contents, such as thickening of the tendon sheaths and the 
presence of intra-articular fluid, have been reported consistently in different studies ${ }^{25,26,31}$ and could lead to CTS increasing the intracompartmental pressure. In our analysis, we found an association between CTS and other musculoskeletal symptoms. In a study on women taking adjuvant AIs compared with women who were not, more patients with AI-related arthralgia had findings consistent with CTS than did those without arthralgia, suggesting that the induction of CTS by AIs may share the same mechanisms of other musculoskeletal symptoms. ${ }^{26}$

Our study has some limitations. Data on the severity and date of resolution of CTS were missing for several women, even after specific inquiries. Diagnosis, management and reporting of CTS were left to local investigators and were therefore heterogeneous, and full clinical details were not captured. Nevertheless, this should not bias our comparative analysis because the study was double blinded, so neither the investigator nor the patient was aware of the treatment. Median follow-up is more than 6 years, and because most cases occur early in the treatment period, we will have captured almost all of the treatment-related cases.

In summary, the use of anastrozole was associated with a higher incidence of CTS, with an excess incidence of $1.8 \%$ after treatment completion. Most CTS cases were of mild to moderate intensity, and only $0.8 \%$ of women taking anastrozole required surgical intervention. Further investigations are warranted that examine the risk factors for CTS, the musculoskeletal symptoms after AI treatment, and the ways in which CTS can be avoided or ameliorated.

\section{AUTHORS' DISCLOSURES OF POTENTIAL CONFLICTS OF INTEREST}

Disclosures provided by the authors are available with this article at www.jco.org

\section{AUTHOR CONTRIBUTIONS}

Conception and design: All authors

Provision of study materials or patients: John F. Forbes

Collection and assembly of data: Ivana Sestak, Anthony Howell

Data analysis and interpretation: Francesco Spagnolo, Ivana Sestak, Jack Cuzick

Manuscript writing: All authors

Final approval of manuscript: All authors

\section{REFERENCES}

1. Chammas M: Carpal tunnel syndrome. Chir Main 33:75-94, 2014

2. Palumbo CF, Szabo RM: Examination of patients for carpal tunnel syndrome sensibility, provocative, and motor testing. Hand Clin 18:269-277, vi, 2002

3. Graham B: The value added by electrodiagnostic testing in the diagnosis of carpal tunnel syndrome. J Bone Joint Surg Am 90:2587-2593, 2008

4. Kaplan $Y$, Kurt SG, Karaer H: Carpal tunnel syndrome in postmenopausal women. J Neurol Sci 270:77-81, 2008

5. Ferny S, Hannaford P, Warskyj M, et al: Carpal tunnel syndrome: A nested case-control study of risk factors in women. Am J Epidemiol 151:566-574, 2000

6. Finsen V, Zeitlmann H: Carpal tunnel syndrome during pregnancy. Scand J Plast Reconstr Surg Hand Surg 40:41-45, 2006

7. Pascual E, Giner V, Aróstegui A, et al: Higher incidence of carpal tunnel syndrome in oophorectomized women. Br J Rheumatol 30:60-62, 1991

8. Geoghegan JM, Clark DI, Bainbridge LC, et al: Risk factors in carpal tunnel syndrome. J Hand Surg [Br] 29:315-320, 2004

9. Confino-Cohen R, Lishner M, Savin $H$, et al: Response of carpal tunnel syndrome to hormone replacement therapy. BMJ 303:1514, 1991

10. Hall GM, Spector TD, Studd JW: Carpal tunnel syndrome and hormone replacement therapy. BMJ 304:382, 1992

11. Sestak I, Sapunar F, Cuzick J: Aromatase inhibitor-induced carpal tunnel syndrome: Results from the ATAC trial. J Clin Oncol 27:4961-4965, 2009

12. Mieog JSD, Morden JP, Bliss JM, et al: IES Steering Committee: Carpal tunnel syndrome and musculoskeletal symptoms in postmenopausal women with early breast cancer treated with exemestane or tamoxifen after 2-3 years of tamoxifen: A retrospective analysis of the Intergroup Exemestane Study. Lancet Oncol 13:420-432, 2012

13. Colleoni $M$, Giobbie-Hurder $A$, Regan $M M$, et al: Analyses adjusting for selective crossover show improved overall survival with adjuvant letrozole compared with tamoxifen in the BIG 1-98 study. J Clin Oncol 29:1117-1124, 2011

14. Dowsett M, Cuzick J, Ingle J, et al: Metaanalysis of breast cancer outcomes in adjuvant trials of aromatase inhibitors versus tamoxifen. J Clin Oncol 28:509-518, 2010

15. Cuzick J, Sestak I, Forbes JF, et al: IBIS-II investigators: Anastrozole for prevention of breast cancer in high-risk postmenopausal women (IBIS-II): An international, double-blind, randomised placebocontrolled trial. Lancet 383:1041-1048, 2014

16. Goss PE, Ingle JN, Alés-Martínez JE, et al: NCIC CTG MAP.3 Study Investigators: Exemestane for breast-cancer prevention in postmenopausal women. N Engl J Med 364:2381-2391, 2011

17. Sestak I, Cuzick J, Sapunar F, et al: ATAC Trialists' Group: Risk factors for joint symptoms in patients enrolled in the ATAC trial: A retrospective, exploratory analysis. Lancet Oncol 9:866-872, 2008

18. Coombes RC, Hall E, Gibson LJ, et al: Intergroup Exemestane Study: A randomized trial of exemestane after two to three years of tamoxifen therapy in postmenopausal women with primary breast cancer. N Engl J Med 350:1081-1092, 2004

19. Partridge AH, LaFountain $A$, Mayer $E$, et al: Adherence to initial adjuvant anastrozole therapy among women with early-stage breast cancer. J Clin Oncol 26:556-562, 2008

20. Henry NL, Azzouz F, Desta Z, et al: Predictors of aromatase inhibitor discontinuation as a result of treatment-emergent symptoms in early-stage breast cancer. J Clin Oncol 30:936-942, 2012

21. O'Connor D, Marshall SC, Massy-Westropp N, et al: Non-surgical treatment (other than steroid injection) for carpal tunnel. Cochrane Database Syst Rev CD003219, 2003
22. Padua L, Padua R, Aprile I, et al: Italian CTS Study Group. Carpal tunnel syndrome: Multiperspective follow-up of untreated carpal tunnel syndrome: a multicenter study. Neurology 56:1459-1466, 2001

23. Llombart-Cussac $A$, Ruiz $A$, Antón $A$, et al: Exemestane versus anastrozole as front-line endocrine therapy in postmenopausal patients with hormone receptor-positive, advanced breast cancer: Final results from the Spanish Breast Cancer Group 2001-03 phase 2 randomized trial. Cancer 118: 241-247, 2012

24. Goss $\mathrm{PE}$, Ingle JN, Pritchard $\mathrm{Kl}$, et al: Exemestane versus anastrozole in postmenopausal women with early breast cancer: NCIC CTG MA.27-a randomized controlled phase III trial. J Clin Oncol 31: 1398-1404, 2013

25. Morales $L$, Pans $S$, Paridaens R, et al: Debilitating musculoskeletal pain and stiffness with letrozole and exemestane: Associated tenosynovial changes on magnetic resonance imaging. Breast Cancer Res Treat 104:87-91, 2007

26. Dizdar O, Ozçakar L, Malas FÜ, et al: Sonographic and electrodiagnostic evaluations in patients with aromatase inhibitor-related arthralgia. J Clin Oncol 27:4955-4960, 2009

27. Lintermans A, Neven P: Pharmacology of arthralgia with estrogen deprivation. 10th Int Aromatase Conf Proc Sept 2010 76:781-785, 2011

28. Blomqvist $A$ : Sex hormones and pain: A new role for brain aromatase? J Comp Neurol 423: 549-551, 2000

29. Felson DT, and Cummings SR: Aromatase inhibitors and the syndrome of arthralgias with estrogen deprivation. Arthritis Rheum 52:2594-2598, 2005

30. Toesca A, Pagnotta A, Zumbo A, Sadun R: Estrogen and progesterone receptors in carpal tunnel syndrome. Cell Biol Int 32:75-79, 2008

31. Nishihori T, Choi J, DiGiovanna MP, et al: Carpal tunnel syndrome associated with the use of aromatase inhibitors in breast cancer. Clin Breast Cancer 8:362-365, 2008 


\section{AUTHORS' DISCLOSURES OF POTENTIAL CONFLICTS OF INTEREST}

Anastrozole-Induced Carpal Tunnel Syndrome: Results From the International Breast Cancer Intervention Study II Prevention Trial

The following represents disclosure information provided by authors of this manuscript. All relationships are considered compensated. Relationships are self-held unless noted. I = Immediate Family Member, Inst = My Institution. Relationships may not relate to the subject matter of this manuscript. For more information about ASCO's conflict of interest policy, please refer to www.asco.org/rwc or jco.ascopubs.org/site/ifc.

Francesco Spagnolo

Honoraria: GlaxoSmithKline, Genentech, Bristol-Myers Squibb

Travel, Accommodations, Expenses: Bristol-Myers Squibb

\section{Ivana Sestak}

No relationship to disclose

\section{Anthony Howell}

No relationship to disclose

\section{John F. Forbes}

No relationship to disclose

\section{Jack Cuzick}

Research Funding: AstraZeneca Speakers' Bureau: NanoString 